\title{
Bahasa Jepang Pelaku Pariwisata di Pantai Kuta
}

\author{
I Made Budiana ${ }^{1)}$, I Nyoman Rauh Artana ${ }^{2)}$ \\ Universitas Udayana \\ budi.hybrid@gmail.com ${ }^{1)}$, rauhartana@gmail.com ${ }^{2}$
}

\begin{abstract}
The arrival of tourists from Japan not only requires tour guides, but also requires human resources who have adequate language competency standards to work professionally. In this study discussed about the variety of Japanese travel agents in the Kuta beach area. This topic was raised because researchers directly saw a lot of tourism actors on Kuta beach, such as hawkers, hair braid services, sellers of nail polish, temporary tattoo, massage services, surfing guide services that use Japanese. However, the Japanese language used is still far from the standard language in Japanese. The variety of Japanese used by tourism actors is very diverse, but irregular so it seems impolite. The purpose of this study is to get a clear picture of Japanese language competence of tourism actors in Kuta beach area. And the results of this study can be used as a basis for making scientific documentation or simple dictionaries that can help tour guides, especially Japanese tour guides.
\end{abstract}

Keywords: guide, tourism, Japanese

\section{Pendahuluan}

Sektor pariwisata merupakan motor penggerak perekonomian di Bali. Sehingga dalam rangka memasuki era globalisasi, pemerintah Indonesia, khususnya Bali, sangat memerlukan sumberdaya manusia yang mampu ikut serta dalam persaingan pasar bebas. Persaingan itu hanya mungkin dilakukan apabila sumber daya manusia tersebut memiliki standar kompetensi pengetahuan dan ketrampilan yang memadai yang sangat diperlukan untuk menunjang pemenuhan kebutuhan dalam kempetensi tertentu, salah satunya adalah kompetensi di bidang pariwisata. Berdasarkan data dari Dinas Pariwisata Provinsi Bali, dapat diketahui bahwa jumlah wisatawan yang berkunjung ke Bali berjumlah cukup banyak. Diantara wisatawan yang berkunjung tersebut, wisatawan Jepang menduduki peringkat ketiga dari dua puluh besar peringkat jumlah wisatawan asing yang berkunjung ke Bali.

Kedatangan para wisatawan yang berasal dari Jepang tidak hanya memerlukan pemandu wisata, tetapi memerlukan juga sumberdaya manusia yang memiliki standar kompetensi yang memadai agar dapat bekerja secara professional. Dalam penelitian ini dibahasa tentang ragam bahasa Jepang pelaku pariwisata di kawasan pantai Kuta. Topik ini diangkat karena peneliti melihat secara langsung banyak sekali pelaku pariwisata di pantai Kuta, seperti pedagang asongan, penjual jasa kepang rambut, cat kuku, tattoo temporary, jasa pijat, jasa pemandu main surfing yang menggunakan bahasa Jepang. Tetapi, bahasa Jepang yang digunakan tersebut masih jauh dari standar bahasa baku di dalam bahasa Jepang. Ragam bahasa Jepang yang digunakan oleh pelaku pariwisata sangat bermacam-macam, namun tidak beraturan sehingga terkesan kurang sopan. Orang Jepang identik dengan budaya timur, artinya orang Jepang sangat memperhatikan sopan satun dan etika dalam berbahasa. Jika para pelaku paraiwisata menawarkan 
dagangan dan jasanya dengan bahasa atau kata-kata yang tidak sopan, maka tawaran yang disampaikan oleh pelaku pariwisata tidak akan direspon dengan baik. Hal ini akan berpengaruh terhadap ketertarikan wisatawan untuk membeli barang atau jasa yang mereka tawarkan dan begitu juga sebaliknya.

Dilandasi oleh rasa keingintahuan peneliti tentang ragam bahasa Jepang yang digunakan oleh pelaku pariwisata di pantai Kuta, maka dilakukan penelitian ini. Dan hasil penelitian ini diharapan dapat memberikan gambaran tentang ragam bahasa Jepang pelaku pariwisata di kawasan pantai Kuta. Selain itu, penelitian ini merupakan studi awal yang akan dijadikan pijakan dalam membuat dokumentasi bahasa atau kamus sederhana yang dapat membantu pemandu wisata, khususnya pemandu wisata asal Jepang.

Masalah penelitian ini dapat dirumuskan sebagai berikut: pertama "Bagaimanakah ragam bahasa Jepang yang digunakan pelaku pariwisata di pantai Kuta?", kedua "Bagaimanakah jenis kosakata yang digunakan pelaku pariwisata di pantai Kuta?"

\section{Metode Penelitian}

Metode penelitian yang digunakan dalam penelitian ini adalah metode penelitian deskriptif kualitatif. Metode penelitian kualitatif sering disebut metode penelitian natutalistik karena penelitiannya dilakukan pada kondisi yang alamiah (natural setting). Penelitian dilakukan pada obyek yang alamiah. Obyek yang alamiah adalah obyek yang berkembang apa adanya, tidak dimanipulasi oleh peneliti dan kehadiran peneliti tidak begitu mempengaruhi dinamika pada obyek tersebut. (Sugiyono,2014:15). Populasi dalam penelitian ini adalah para pelaku pariwisata di kawasan pantai Kuta. Teknik pengumpulan data yang digunakan untuk penelitian ini ada tiga, yaitu: Pertama teknik observasi terstuktur, merupakan teknik yang dilakukan apabila peneliti telah tahu dengan pasti tentang variabel apa yang akan diamati (Sugiyono : 2013). Observasi yang dilakukan pada penelitian ini adalah untuk memperoleh gambaran yang jelas mengenai bahasa Jepang yang digunakan pelaku pariwisata di kawasan pantai Kuta. Teknik yang kedua adalah wawancara semi-terstruktur, yaitu Tanya jawab bebas dimana peneliti hanya menyusun pertanyaan berupa garis-garis besar permasalahan yang akan ditanyakan (Sugiyono :2013). Data yang dicari dalam penelitian ini, yaitu mengenai hal yang berkaitan dengan fokus penelitian, yakni bahasa Jepang pelaku pariwisata di pantai Kuta. Teknik yang terakhir adalah tekni catat, teknik catat dalam penelitian ini dimaknai sebagai tindakan merekam bentuk-bentuk bahasa Jepang yang dipakai untuk berkomunikasi oleh pelaku pariwisata di kawasan pantaiu Kuta. Analisis data digunakan metode agih dan metode padan. Metode agih adalah metode analisis yang alat penentunya berada pada bagian dari bahasa yang bersangkutan itu sendiri Sudaryanto (1993: 5). Metode padan adalah metode analisis yang alat penentunya diluar, terlepas, dan tidak menjadi bagian dari bahasa yang bersangkutan. Peneliti menggunakan teknik lanjutan dalam metode padan berupa teknik pilah unsur penentu. Metode ini digunakan untuk mengetahui ragam bahasa Jepang yang digunakan oleh pelaku pariwisata di kawasan pantai Kuta.

Penelitian ini merupakan deskripsi mengenai ragam bahasa Jepang yang digunakan oleh pelaku pariwisata di kawasan pantai Kuta. Bahasa yang digunakan pada umumnya adalah bahasa pasaran, yang mana bahasa tersebut tidak sesuai dengan kaidahkaidah baku di dalam bahasa Jepang. Pelaksanaan penelitian ini diawali dengan mongobservasi ragam bahasa atau bentuk bahasa yang digunakan pelaku pariwisata di kawasan pantai Kuta. Langkah kerja selanjutnya adalah: mengidentifikasi, mengklasifikasi, dan menyesuaikan dengan teori, mengumpulkan data. Apabila data 
telah dikumpulkan, maka langkah berikutnya adalah analisis data. Hasil analisa data kemudian dilaporkan dalam bentuk tulisan deskriptif dan diikuti dengan simpulan dan saran.

\section{Pembahasan}

Kosakata 'goi' dalam bahasa Jepang adalah keseluruhan kata yang berkenaan dengan suatu bahasa atau bidang tertentu yang ada didalamnya (Shinmura, 1998 : 875). Sejalan dengan pernyataan Shinmura, Machi Hiromitsu (dalam Sudjianto dan Dahidi, 2004 : 97-98) memberikan konsepsi goi yang menyatakan bahwa kanji /i/ 彙 pada kata /goi/ 語彙 atsumeru koto 'kumpulan' atau 'himpunan'. Oleh sebab itu, goi dapat didefinisikan sebagai go no mure atau go no atsumari 'kumpulan kata'. Ruang lingkup pengumpulan kata dapat ditunjukkan dengan berbagai cara. Dari pendapat di atas, dapat disimpulkan bahwa goi 'kosakata' dalam bahasa Jepang adalah kumpulan kata yang berhubungtan dengan bidang tertentu dalam bahasa itu.

Jenis-Jenis goi 'kosakata' bahasa Jepang dapat diklasifikasikan berdasarkan; 1) karakteristik gramatikalnya, yatu doushi 'verba', i-keyoushi 'adjektiva-i', keyoudoshi 'adjektiva-na', meishi 'nomina', rentaishi 'prenomina', fukushi 'adverbia', kandoushi 'interjeksi', setsujokushi 'konjungsi', jodoushi 'verba bantu', dan joshi 'partikel'. 2) klasifikasi goi berdasarkan penuturnya yang dilihat dari factor usia, jenis kelamin, dan sebagainya, seperti: jidougo atau youjigo 'bahasa anak-anak', wakamono kotoba 'bahasa anak muda', roujingo 'bahasa orang tua', joseigo atau onna kotoba 'ragam bahasa wanita', danseigo atau otoko kotoba 'ragam bahasa pria', gakusei yougo atau gakuseigo 'bahasa mahasiswa'. 3) klasifikasi goi berdasarkan pekerjaan atau bidang keahliannya, yaitu: senmon yougo 'istilah-istilah bidang profesi atau keahlian', seperti: isha 'dokter', sensei 'dosen atau guru', ginkoin ' karyawan bank', seijika 'politikus', shashinka 'potografer', dan lain sebagainya. 4) klasifikasi goi berdasarkan perbedaan zaman dan wilayah penuturnya, yaitu ada kata-kata yang tergolong pada bahasa klasik, bahasa modern, dialek Hiroshima, dialek Kansai, dialek Tokyo. 5) klasifikasi goi berdasarkan kosakata hyougen goi atau shiyou goi, rikai goi, kihon goi, rikai goi, kihon goi, kiso goi, doo'on goi, igigo, ruigigo, keigo yang didalamnya mencakup kosakata sonkeigo, kenjougo, tenei go, dan futsuu go. 6) berdasarkan asal-usulnya kosakata bahasa Jepang dibagi menjadi 3 macam, yaitu wago, kango dan gairaigo. Wago adalah kosakata asli Jepang yang telah ada sebelum masuknya pengaruh bahasa China ke dalam bahasa Jepang, namun dikatakan juga bahwa ada beberapa kata wago yang merupakan kosakata yang diserap dari bahasa China. Kango adalah kosakata yang digunakan dalam bahasa Jepang yang berasal dari China.Walaupun kango memiliki kesamaan dengan gairaigo sebagai kosakata yang diserap dari bahasa asing, namun karena wago yang diserap dari bahasa China memiliki karakteristik tertentu, maka tidak digolongkan ke dalam gairaigo. Pengertian Gairaigo menurut Sudjianto dan Ahmad Dahidi, (2004:104) adalah kata-kata yang berasal dari bahasa asing (gaikokugo) yang lalu dipakai sebagai bahasa nasional (kokugo).

Bahasa Jepang mempunyai tingkat hormat yang sejajar dengan bahasa Jawa dan bahasa daerah lainnya di Indonesia, seperti bahasa madura, bahasa sunda dan lainnya. Diantara para pembelajar bahasa Jepang pada umumnya ada yang dapat dan senang menggunakan keigo (ragam bahasa hormat) dan ada juga yang tidak. Orang Jepang sendiri terlebih para anak mudanya tidak begitu suka menggunakannya karena bahasa hormat dianggap sulit menurut mereka. Mereka akan mulai belajar menggunakan sonkeigo dan kenjougo apabila mereka bekerja di instasi perusahaan yang memaksanya untuk memakainya karena tuntutan pekerjaan. 
Dalam buku Reikai Shinkokugo Jiten (1987:279) keigo adalah 話してや聞き手が読み手や、ま た話題に上がっている人や、物事に対して、敬意を表したり、丁寧に表現したりするために使う言葉。 Hanashiteya, kikite ga yomite ya, mata wadai ni agatte iru hito ya, monogoto ni taishite, keii o arawashitari, teinei ni hyougen shitari suru tame ni tsukau kotoba. 'Ungkapan yang dipakai oleh pembicara ataupun penulis untuk menyatakan perasaan hormat dan sopan santun terhadap lawan bicara, pembaca dan orang yang dibicarakan'. Dijelaskan juga dalam Kamus Pemakaian Bahasa Jepang Dasar, keigo adalah 'Ungkapan yang menunjukkan tingkat kehormatan yang dibedakan menurut hubungan tinggi dan rendahnya kedudukan atau tingkat keakraban diantara pembicara dan pendengar atau orang yang sedang dibicarakan (terutama yang menunjukkan rasa hormat terhadap pendengar atau orang yang dibicarakan) (1988:524).

Dalam bahasa Jepang ragam bahasa hormat meliputi ragam 普通 Futsu 'biasa' dan 丁寧 Teinei 'hormat' (敬語 keigo). Secara singkat Terada Takanao menyebut keigo sebagai bahasa yang mengungkapkan rasa hormat terhadap lawan bicara atau orang ketiga (Terada, 1984:238). Hampir sama dengan pendapat itu, ada juga yang mengatakan bahwa keigo adalah istilah yang merupakan ungkapan kebahasaan yang menaikkan pendengar atau orang yang menjadi pokok pembicaraan (Nomura, 1992:54). Pada dasarnya keigo dipakai untuk menghaluskan bahasa yang dipakai orang pertama (pembicara atau penulis) untuk menghormati orang kedua (pendengar atau pembaca) dan orang ketiga (yang dibicarakan). Dalam tingkat tutur bahasa Jepang mengenal konsep うち uchi 'dalam' dan soto そと 'luar', artinya orang Jepang akan memperhatikan dengan siapa berbicara, dan siapa yang dibicarakan. Misalnya ketika berbicara di kantor sendiri antara bawahan dan atasan ragam yang akan digunakan bawahan adalah ragam menghormat 尊敬語 sonkeigo 'bahasa menghormat' dalam rangka menghormati atasannya, akan tetapi ketika bawahan itu berbicara dengan orang lain dari kantor yang berbeda ragam yang digunakan adalah ragam 謙譲語 kenjoogo 'bahasa merendah', sekalipun yang dibicarakan adalah atasannya sendiri.

\section{Bentuk Tingkatan Bahasa dalam Bahasa Jepang}

Pada awalnya, pembelajar bahasa Jepang dikenalkan dengan tingkatan teineigo terlebih dulu disamping itu tingkatan bahasa hormat yang lain seperti sonkeigo dan kenjoogo, sebab tingkatan teineigo dipakai secara luas untuk menghormati kepada mitra wicara.

\section{1) Tingkatan Teineigo}

Kata teinei berarti sopan, sehingga bentuk teineigo biasa diartikan dengan bentuk sopan. Karena tingkatan teineigo ini kalimatnya berakhiran dengan kopula -desu, atau verba bantu-masu, maka disebut pula ragam desu atau masu. Tingkatan teineigo merupakan salah satu bagian dari keigo (bahasa hormat) bahasa Jepang. Pembicara menggunakan tingkatan ini untuk menyatakan rasa hormat dan biasanya memperindah suatu pokok pembicara secara langsung terhadap mitra wicaranya. Umumnya bentuk tingkatan ini mempunyai ciri-ciri: kalimat akhirnya berakhiran dengan kopula - desu dan verba bantu -masu. Contoh kalimat: (1) Miruku o nomimasu 'Saya minum susu'; (2) Nihonryouri wa oishii desu 'Masakan Jepang enak'; (3) Hantoshi gurai naraimashita 
'Saya telah belajar kira-kira setengah tahun'; (4)Kono ryouri wa oishikunai desu 'Masakan ini tidak enak'; (5) Ano ie wa ookii desu 'Rumah itu besar'.

Contoh verba nomimasu 'minum' merupakan contoh tingkatan teineigo yang berasal dari perubahan verba nоти dan verba naraimashita 'belajar'(lampau) berasal dari verba narau (futsuu'biasa'). Untuk mengubah verba dalam tingkatan futsuugo menjadi tingkatan teineigo caranya dengan menambahkan verba bantu masu dan mashita (lampau). Dalam kamus bahasa Jepang, verba-verba dalam bahasa Jepang umumnya hanya dapat dijumpai dalam bentuk futsuugo. Sedangkan oishii 'enak' dan ooki ' 'besar'merupakan contoh kata sifat yang berakhiran i (ikeyoushi). Untuk mengubah kata sifat, dan kata benda dalam bahasa Jepang yang masih berbentuk tingkatan futsuugo agar menjadi tingkatan teineigo, maka tinggal menambahkan kopula desu dibelakang kata sifat dan kata benda tersebut.

\section{2) Tingkatan Futsuugo}

Tingkatan futsuugo dalam bahasa Jepang merupakan tingkatan yang paling dasar, maksudnya tingkatan ini dipakai oleh pembicara kepada lawan bicaranya yang sudah akrab. Tingkatan futsuugo mempunyai ciri-ciri sebagai berikut: 1) berakhiran dengan $\sim d a$, atau de aru b. berakhiran dengan verba bentuk futsuukei, seperti bentuk $\sim r u$ Contoh kalimat:Seitotachi wa bun o tsukuru 'Murid-murid membuat kalimat'; 2)Kono yakimeshi wa totemo umai Nasi goreng ini enak sekali'; 3) Taoru ya sekken nado o katta 'Saya telah membeli handuk, sabun, dan lain-lain' ; 4) Ishida-kun wa namakemono dewa nai 'Ishida bukan pemalas'; 5) Kore wa yasui mono da. 'Ini barang yang murah'

Pada contoh-contoh kalimat, tingkatan futsuugo, verba futsuugo tidak mengalami perubahan. Sedangkan dalam bentuk lampau mengalami perubahan, seperti: tsukuru 'membuat' dan katta (bentuk lampau) dari kau 'membeli'. Pada contoh kalimat yang memakai kata sifat ikeyoushi tidak mengalami perubahan, hanya saja jika kata sifatnya berubah menjadi bentuk negatif maka cukup menambahkan nai atau dewa nai (kata sifat berakhiran na/kata benda) dibelakangnya, sedangkan pada kata benda tinggal menambahkan kopula $d a$.

\section{3) Tingkatan Sonkeigo}

Tingkatan sonkeigo adalah bagian tingkatan keigo (bahasa hormat) bahasa Jepang yang dipakai untuk menghormat kepada lawan bicaranya. Umumnya tingkatan ini verbanya mempunyai ciri-ciri mendapat imbuhan verba bantu -o...ni naru, -rareru, serta mempunyai bentuk verba khusus dalam sonkeigo dan nominanya berimbuhan prefiks go/o. Contoh kalimat: 1) Buchou wa Amerika e shutchou nasaimasu 'Pak Direktur akan dinas ke Amerika'; 2) Kachou wa mou kaeraremashita 'Pak Manager sudah pulang'; 3) Sensei wa irrashaimasu ka 'Pak Guru ada?'; 4) Okosan no namae wa nanto osshaimasu $k a$ ? 'Siapa nama putra anda?'; 5)Sensei wa atarashii pasokon wo kai ni narimashita 'Pak Guru telah membeli computer baru'.

Pada contoh kalimat, verba nasaimasu 'melakukan' berasal dari verba shimasu (teineigo) kemudian verba suru (futsuugo) dan osshaimasu 'berkata' berasal dari verba iimasu (teineigo) kemudian verba iu (futsuugo). Contoh perubahan verba songkeigo dari teineigo dan verba teineigo dari futsuugo mengalami perubahan yang cukup dinamis. Aturan tersebut sudah paten ditentukan dalam verba khusus dalam aturan yang ada dalam tingkatan sonkeigo. Kemudian ada juga verba futsuugo yang diubah menjadi tingkatan sonkeigo dengan menambahkan verba bantu ni naru dan verba bantu reru, contoh: kai 
ni narimasu berasal dari kau (futsuugo) 'membeli' dan kaeraremasu berasal dari verba kaeru (futsuugo) 'pulang'.

\section{4) Tingkatan Kenjoogo}

Tingkatan kenjougo merupakan salah satu bagian dari keigo ((bahasa hormat) bahasa Jepang yang dipakai terhadap lawan bicara atau terhadap orang yang dibicarakan dengan cara merendahkan diri. Umumnya bentuk tingkatan kenjoogo mempunyai ciri-ciri verbanya terdiri dari verba khusus kenjoogo, verba bantu go/o...suru dan nominanya juga ditambahkan dengan prefiks o/go didepannya.

Contoh kalimat: 1) Watakushi wa Amerika kara, mairimashita 'Saya datang dari Amerika'; 2) Kaisha no naka o goannai shimasu 'Saya akan memandu dalam perusahaan'; 3) Nyuyouku ni orimasu 'Berada/di New York'; 4) Ima, dekakete orimasu 'Sekarang sedang keluar'; 5) Kinou sensei no otaku e ukagaimashita 'Kemarin saya berkunjung ke rumah Pak Guru'. Dalam tingkatan kenjoogo kata kerja golongan I, kata kerja golongan II, dan perubahan verba dari bentuk futsuu ke teinei dan verba dari teinei ke kenjoogo juga mengalami perubahan bentuk yang cukup dinamis. Misalnya verba mairimasu (kenjoogo) berasal dari verba kimasu (teineigo), kemudian dari verba kuru 'datang' (futsuugo), dan verba ukagaimasu (kenjoogo) berasal dari kata uchi e ikimasu (teineigo) kemudian dari verba uchi e iku (futsuugo). Aturan tersebut sudah paten ditentukan dalam bentuk verba khusus dalam aturan yang ada dalam bentuk kenjoogo. (dikutip dari tautan google, yaitu Blog SEPUTAR BAHASA JEPANG yang terbit pada hari Kamis, 03 Oktober 2013)

Pada uraian di bawah ini merupakan data-data ragam bahasa Jepang dan Jenis kosakata yang digunakan pelaku pariwisata di pantai Kuta.

Data: 1 (satu)

1. Biasanya pedagang acung memastikan apakah tamu di pantai yang diajak berbicara, orang china, korea, atau orang Jepang dengan kata bertanya:

"you Chinese?"

"you Korea"

"Nihon Jin"

Kalau orang yang mereka yang mereka Tanya orang Jepang, maka pedagang acung akan berbicara dalam bahasa Jepang dengan semampunya untuk menawarkan barang dagangannya.

Berikut di bawah ini adalah kosakata yang mereka gunakan dalam berkomunikasi dengan orang Jepang.

1. Ikko-ikko/ hitotsu-hitotsu, yasui-yasui 'menawarkan barang-barang aksesoris, yaitu: gelang, kalung, kacamata, dan pernak-pernik lainnya. Selain itu, pedagang acung juga menawarkan pakaian, seperti: celana, baju kaos, topi, rompi yang semuanya bermotif identitas budaya Bali. Ketika pedagang acung menawarkan barang dagangannya kepada touris Jepang, dan touris Jepang menjawab dengan kata "takai-takai' (mahal), "iranai" (tidak/ tidak perlu)

2. Pedagang acung tanya orang Jepang "Bari Hajimete ?" kore, ikko, yasui ne" pertanyaan ini biasanya ditujukan pada touris Jepang yang baru datang ke Bali. Pedagang akan menawarkan barangnya dengan harga yang mahal-mahal karena apabila touris Jepang tersebut barau pertama kali datang ke Bali, karena pedagang berpikir bahwa tamu yang baru datang pertama kali tidak akan memahami harga-harga yang sebenarnya dan taamu yang baru datang biasanya langsung membeli tanpa menawar. 
3. Pedagang acung, yaitu penjual aksesoris, patung, kipas, gantungan kunci, cincin biasanya menawarkan barang dagangannya dengan kosakata bahasa Jepang, seperti: 'yasui yo, 'murah lo' ichiman dake yo, 'Cuma sepuluh ribu saja lo' waribiki suru yo' 'boleh ditawar/boleh kurang lo' pada umumnya pedagang acung berbicara bahasa Jepang namun dengan pola bahasa Indonesia mereka berusaha memnakai bahasa sepengetahuannya untuk menarik perhatian touris Jepang. Dan orang Jepang menjawab dengan mengikuti pola bahasa yang dipakai oleh pedagang acung, yaitu menjawab dengan kata 'takai-takai' (mahal-mahal)

Data: 2 (dua)

Ragam bahasa Jepang

Kosakata: Informan dari Kintamani/perempuan, pedagang acung jualan gelang dan kepang rambut.

1. Futsuu-kei (bentuk biasa)

1. Tanya pedagang: 'Yasui-yasui, ichiman rupe' jawab org Jepang 'Moo ii-moo ii

2. Tanya pedagang: 'Nihon doko' jawab org Jepang 'kanagawa'

3. Orang Jepang Tanya 'doko karakimashita ka'? pedagang acung menjawab 'yama no hoo' (arah gunung'. 'Kore., kau-kau, kau kudasi'. Akhirnya, pedagang acung minta tolong sama guide agar dagangannya mau dibeli sama touris Jepang.(dalam bahasa Bali 'tiyang ngidih tulung, tulingin je pang beline barang tyange pak') Bapak yang menjadi guide berkata pada touris Jepang tersebut 'seikaku Bari ni kita node, katte kudasai' (karena susah payah sudah datang ke Bali belilah barangnya). Wisatawan Jepang menjawab 'ii desu yo', kawaiso ne' (baiklah saya beli, kasihan).

Data: 3 (tiga)

pedagang acung 'harumaki-harumaki' (lumpiang-lumpiang). Orang Jepang menolak, karena orang Jepang tidak suka yang berminyak.

Data: 4 (empat)

'Safingu 200.000 'nijuuman rupee' pemandu surfing berkeliling di depan wisatawan asal Jepang menawarkan jasanya untuk memandu main selancar dengan biaya 200 ribu.

Data: 5 (lima)

Penjual gelang: kau-kau, ikkoo katte, goman rupee

taberu-taberu

kau-kau

yasui-yasui

dore-dore

katte-katte

mereka sering mengulang-ulang leksikon.

Data: 6 (enam)

1. Jikan aru? L/W

2. Chotto ii? $\mathrm{L} / \mathrm{W}$

3. Mou ikkai: satu kali lagi. $\mathrm{L} / \mathrm{W}$

4. Motto yukkuri: agak pelan sedikit/ lebih pelan. L/W 
5. Motto tsuyoku: agak kuat sedikit/ lebih kuat. L/W

6. Motto hayaku: agak cepat sedikit. L/W

7. Motto yasashiku. L/W

8. Piru nonderu? L apakah kau minum pil

9. Daijoubu-yo. W

Daijoubu-dayo. L

Heiki-ayo. L/w

10. Chotto achi muitete. L/W maukah kamu menengok ke sini sebentar saja

11. Shimpai Shinai-de. L/w jangan khawatir

12. Hajimete ?L/w apakah ini yang pertama kali bagimu?

13. Hazukashi-garanai-de. L/P jangan malu-malu

14. Doko-ni? L/w Di mana?

15. Watashi $O$ mite. W. lihat aku

Boku O mite. L

16. Oshiete-ageru. L/w aku akan kasih tahu kamu

Data: 7 (tujuh) Josei go dan dansei go

1. Mata atta-ne. W Senang bertemu kamu lagi.

2. Mata atta na. L

Walaupun matta atta-ne adalah frasa khusus wanita, namun seorang pria harus menggunakannya ketika berbicara dengan seorang gadis, bukannya mata atta-na yang kurang sopan.

Data: 8 (delapan)

1. Hisashiburi-ne. W Kau lama tidak kelihatan

2. Hisashiburi-dane. $\mathrm{W} / \mathrm{L}$

Bisa diubah:

1. Hisashiburi-nee? $\mathrm{W}$

2. Hisashiburi-danee? W/L

Ada dua cara untuk mengungkapkan ne: ne pendek (ne) diucapkan dengan intonasi menurun untuk menyatakan persetujuan atau untuk menambahkan keramahan pada percakapan; dan ne panjang (nee) diucapkan dengan intonasi menaik, sering berarti "bukan?/Iya kan" atau "Ya", jadi meminta persetujuan.

Wanita lebih suka mengucapkan ne dan nee, jadi pria harus memiliki alternative yang sesuai: na dan naa. Akan tetapi apabila pria ingin menata pembicaraan mereka, mereka harus menggunakan ne dan nee, terutama pada saat berbicara pada lawan jenisnya.

Arti dari beberapa frasa bisa diubah dari pernyataan ke pertanyaandengan mengubah ne ke nee. Seperti frtasa yang dijelaskan di atas. Kencana (xi)

Data: 9 (Sembilan)

Kosakata dan Kalimat

1. Genki? L/w apa kabar

Jawaban: 1. Genki. L/W

2. Genki-yo. W

3. Genki-dayo. L/W

4. Maane. L/W

2. 1.Dou Shita? L/w artinya anda tahu apa yang sedang terjadi, tapi ada bagian yang terlewatkan yang tidak anda ketahui. 
2.Nanka atta no? L/W artinya anda tidak tahu apa yang sedang terjadi

3. Nani yatteta-no? L/W pertanyaan seorang pemandu surfing kepada turis Jepang.

\section{Simpulan}

Berdasarkan hasil observasi menunjukkan bahwa pelaku pariwisata di pantai Kuta pada saat berkomunikasi dengan wisatawan asal Jepang menggunakan ragam bahasa yang tidak beraturan/ bahasa yang tidak sesuai dengan kaidah penggunaannya. Pola kalimat yang digunakan mengacu kepada bahasa ibu yaitu bahasa Indonesia dengan kosakata bahasa Jepang. Kemampuan berbahasa Jepang para pelaku pariwisata di pantai Kuta tidak diperoleh dari belajar secara formal, tetapi diperoleh dengan cara mendengar dari orang lain yang kebetulan berkomunikasi dengan menggunakan bahasa Jepang. Selain itu, pelaku pariwisata juga menggunakan bahasa tubuh pada saat menawarkan barang dangan atau jasanya dengan gerakan-gerakan anggota badan untuk membantu komunikasinya. Sejalan dengan hal tersebut di atas, (AA Tirta Putra Wiranata,dkk: 2016) menyatakan bahawa jenis bahasa yang digunakan pelaku pariwisata di pantai Kuta termasuk ke jenis bahasa pidgin, karena bahasa yg digunakan tidak memiliki kriteria "native speaker" (pembicara asli), dimana terdapat pernyataan Native Speaker menurut Bloomfield (1933) dalam buku Language yaitu: "The first language a human being learns to speak is his native language; he is a native speaker of this language" Bahasa pidgin terbukti sampai saat ini masih digunakan oleh pedagang asongan di Pantai Kuta untuk berinteraksi, dikarenakan wisatawan mancanegara masih paham dengan apa yang dimaksud, walaupun pada prosesnya terdapat sedikit praktek pemaksaan dari si pedagang. Dengan demikian, di dalam proses interaksi antara pelaku pariwisata dengan wisatawan mancanegara terdapat noise (ketidak saling pahaman saat berkomunikasi, DeVito : 1997), sehingga agar kedua pihak saling memahami, mereka lebih menggunakan cara non-verbal atau dengan gerak gerik tubuhnya

Jenis kosakata yang digunakan adalah oleh pelaku pariwisata di pantai Kuta dapat diklasifikasikan sebagai berikut: (1) berdasarkan karakteristik gramatikalnya, kelas kata yang digunakan, yatu doushi 'verba', i-keyoushi 'adjektiva-i', keyoudoshi 'adjektiva-na', meishi 'nomina', rentaishi 'prenomina', fukushi 'adverbia', kandoushi 'interjeksi', setsujokushi 'konjungsi', jodoushi 'verba bantu', dan joshi 'partikel'. 2) klasifikasi kosakata berdasarkan penuturnya yang dilihat dari faktor usia, jenis kelamin, dan sebagainya, seperti: jidougo atau youjigo 'bahasa anak-anak', wakamono kotoba 'bahasa anak muda', roujingo 'bahasa orang tua', joseigo atau onna kotoba 'ragam bahasa wanita', danseigo atau otoko kotoba 'ragam bahasa pria', gakusei yougo atau gakuseigo 'bahasa mahasiswa'. 3)klasifikasi kosakata hyougen goi atau shiyou goi, rikai goi, kihon goi, rikai goi, kihon goi, kiso goi, doo'on goi, igigo, ruigigo, keigo yang didalamnya mencakup kosakata sonkeigo, kenjougo, tenei go, dan futsuu go. 6) berdasarkan asal-usulnya kosakata, yaitu wago, kango dan gairaigo.

\section{Daftar Pustaka}

Allan, Keith. 2001. Natural Language Semantics. Blackwell.

Andayani, N. L. Henny dan N. Nym Yulianthini. 2012. Pengembangan Selancar (Surfing) di

Kawasan Wisata Pantai Kuta, Kabupaten Badung Melalui Pemberdayaan Masyarakat (Community Based Development). Singaraja : Jurusan D3 Perhotelan, Fakultas Ekonomi dan Bisnis, UniversitasPendidikan. 
Beratha, N.L. Sutjiati. 1999. Variasi Bahasa Inggris pada Kawasan Pariwisata di Bali. Bali :

Program Studi Sastra Inggris, Fakultas Sastra, Universitas Udayana.

Chaer, Abdul. 1994. Linguistik Umum. Jakarta: PT. Rineka Cipta.

Goddard, Cliff. 1997. Semantic Analysis: A Practical Introduction. Australia: The University Of New England.

Mahsun, 2005. Metode Penelitian Bahasa: Tahapan Strategi, Metode, dan Tekniknya. Jakarta: PT Raja Grafindo Perkasa

Markhamah, Atiqa Sabardila. 2009. Analisis Kesalahan dan Kesantunan Berbahasa.

Surakarta: Muhammadiyah University Press

Sudaryanto. 1993. Metode dan Teknik Analisis Bahasa, Pengantar Penelitian

Wahana Kebudayaan Secara Linguistik. Yoyakarta: Universitas Gajah Mada.

Sudjianto dan Dahidi, A. 2004. Pengantar Linguistik Bahasa Jepang.

Jakarta: Kesaint Blanc.

Verhaar, J.W.M. 2001. Asas-Asas Linguistik Umum. Cetakan ketiga. Yogyakarta: Gajahmada University Press. 